Recebido em 04/2018. Aceito para publicação em 12/2018.

\title{
POLÍTICA NACIONAL DE RESÍDUOS SÓLIDOS E SUA GESTÃO NOS MUNICÍPIOS DO LITORAL NORTE DO ESTADO DE SÃO PAULO
}

\section{NATIONAL SOLID WASTE POLICY MANAGEMENT IN THE NORTHERN COAST MUNICIPALITIES OF THE SÃO PAULO STATE}

\author{
Eliete Gianini de Oliveira ${ }^{1}$ \\ Mário Valério Filho ${ }^{2}$ \\ Rodolfo Moreda Mendes ${ }^{3}$
}

\begin{abstract}
Resumo: Este artigo tem como objetivo a análise das políticas públicas voltadas ao sistema de coleta e destinação dos resíduos sólidos urbanos na região do Litoral Norte do Estado de São Paulo, composta pelos municípios de Caraguatatuba, Ilhabela, São Sebastião e Ubatuba. A análise foi realizada através dos dados primários obtidos a partir de questionário elaborado e enviado aos gestores responsáveis pelo manejo de resíduos sólidos urbanos de cada município da região de estudo. A análise foi conduzida tomando-se como base as recomendações da Política Nacional de Resíduos Sólidos, instituída pela Lei Federal n. 12.305 de 02 de agosto de 2010 e regulamentada através do Decreto n. 7.404/2010, considerada um marco nas questões de resíduos sólidos no País. Pelos resultados alcançados constatouse que os municípios do Litoral Norte Paulista apresentam bom desempenho se comparados aos índices nacionais, porém são observadas várias possibilidades de melhoria. Na comparação entre os quatro municípios da região, o que obteve posição de destaque foi o município de São Sebastião, seguido pelos municípios de Caraguatatuba e Ilhabela; o município que apresentou resultados desfavoráveis foi Ubatuba.
\end{abstract}

Palavras-chave: Resíduos sólidos urbanos; Política Nacional de Resíduos Sólidos; políticas públicas.

\begin{abstract}
The objective of this article is analyze public policies for the collection and disposal of solid urban waste in the North Coast region of the State of São Paulo, which includes the municipalities of Caraguatatuba, Ilhabela, São Sebastião and Ubatuba. The analysis was performed through the primary data obtained from a questionnaire prepared and sent to the managers responsible for the management of solid urban waste, from each municipality studied. The analysis was conducted based on the recommendations of the National Policy of Solid Waste, established by Federal Law number 12.305 and regulated by Decree number 7.404/2010, a milestone in solid waste issues in the country. Based on the results obtained, it was found that the municipalities of the North Coast of São Paulo show good performance compared to the national indices, but several possibilities for improvement are observed. In the comparison between the four municipalities studied, the São Sebastião municipality had the best performance, followed by Caraguatatuba and Ilhabela municipalities, and the Ubatuba municipality had the worst results.
\end{abstract}

Keywords: Urban Solid Waste; National Policy of Solid Waste; Public Policies.

\section{INTRODUÇÃO}

Considerando que o homem deixou de ser nômade e que toda atividade humana gera resíduos, a tendência é que os resíduos permanecendo no local de origem sejam

\footnotetext{
${ }^{1}$ Mestre em Planejamento Urbano e Regional, Instituto de Pesquisa e Desenvolvimento (IP\&D), Universidade do Vale do Paraíba - Univap, Brasil. E-mail: eli.sjc78@gmail.com.

2 Docente do Programa em Planejamento Urbano e Regional, Instituto de Pesquisa e Desenvolvimento (IP\&D), Universidade do Vale do Paraíba - Univap, Brasil. E-mail: mvalerio@univap.br.

${ }_{3}$ Pesquisador Associado II do Centro Nacional de Monitoramento e Alertas de Desastres Naturais - Cemaden, Brasil. E-mail: rmm.cemaden@gmail.com.
} 
devidamente gerenciados para evitar transtornos à população local. Dentre os diversos transtornos, bem conhecidos do povo brasileiro, podemos citar: enchentes, alagamentos, doenças causadas devido a proliferação de vetores, contaminação de corpos d'água e outras mais.

Os municípios do Litoral Norte Paulista têm restrições para realizar a destinação de resíduos sólidos urbanos frente à Política Nacional de Resíduos Sólidos, porque estão inseridos em uma região vulnerável ambientalmente, por ser uma planície litorânea de solo, predominantemente arenoso e com o lençol freático raso, além de ser uma região de turismo de massa, que nos meses de temporada tem a quantidade de resíduos aumentada. Essas condições impróprias mencionadas são alguns dos fatores complicadores tanto para implantação de aterro sanitário quanto para a exportação de resíduos.

Em 02 de agosto de 2010 foi instituída a Política Nacional de Resíduos Sólidos (PNRS), por meio da Lei Federal n. 12.305 (BRASIL, 2010a) e a sua regulamentação através do Decreto n. 7.404/2010 (BRASIL, 2010b), sendo um marco nas questões de resíduos sólidos no país. Após vinte e um anos de tramitação no Congresso Nacional, esta lei que envolveu poder público, consumidor e o setor produtivo, tornou esses setores responsáveis pela gestão de resíduos sólidos. Em seu artigo 9a a PNRS define a ordem de prioridade que deve ser adotada na gestão e gerenciamento de resíduos sólidos, sendo ela: não geração, redução, reutilização, reciclagem, tratamento dos resíduos sólidos e disposição final ambientalmente adequada dos rejeitos.

O Plano Municipal de Gestão Integrada de Resíduos Sólidos (PMGIRS) é um dos principais instrumentos para auxiliar os municípios na difícil tarefa de realizar a gestão de resíduos sólidos, mas ele sozinho não garante o atendimento à PNRS. Segundo dados da Pesquisa de Informações Básicas Municipais - MUNIC do Instituto Brasileiro de Geografia e Estatística (IBGE) de 2013, dos 5.570 municípios do Brasil somente $1.865(33,5 \%)$ declararam possuir Plano Municipal de Gerenciamento Integrado de Resíduos Sólidos (PMGIRS). A gestão de resíduos é um assunto bastante complexo, que junto com a definição de prioridade têm se mostrado um grande desafio aos municípios, tendo em vista a árdua tarefa de disciplinar os atores envolvidos no planejamento e gestão dos resíduos gerados com o compromisso de políticas ambientalmente corretas.

De acordo com Betio e Santos (2016), os resíduos sólidos urbanos após coletados, transportados e acondicionados devem ser dispostos em um local devidamente controlado. Dependendo das características ambientais e construtivas, esses locais podem ser classificados como aterros sanitários ou "lixões". Nos aterros sanitários existem sistema de proteção contra a poluição dos solos e corpos d'água. Já no sistema de "lixão" esses locais são caracterizados pela ausência de planejamento medidas de proteção contra poluição, onde os resíduos são dispostos a céu aberto. As áreas de "lixão" se tornam fontes potenciais de contaminação contínua, 
mesmo quando encerradas, essas áreas devem ser monitoradas até que apresentem parâmetros aceitáveis pela legislação nacional.

O presente artigo busca analisar a problemática referente à gestão e destinação final dos resíduos sólidos urbanos nos municípios do Litoral Norte Paulista sob à luz da Política Nacional de Resíduos Sólidos Urbanos. Neste contexto foram levantadas as informações necessárias através de questionário enviado aos gestores de resíduos sólidos urbanos dos municípios abordados no estudo, possibilitando analisar a problemática da gestão e destinação final dos resíduos sólidos urbanos da região.

\section{POPULAÇÃO, PADRÃO DE CONSUMO E O AUMENTO NA GERAÇÃo DE RESÍDUOS}

O crescimento populacional no Brasil, que se deu na segunda metade do século $\mathrm{XX}$, assim como nos demais países da América Latina, apresentou um processo de urbanização intenso. A população urbana no Brasil cresceu de 26,3\% em 1940, para $81,2 \%$ em 1980 (MARICATO, 2001, p. 16). Não se pode atribuir o aumento da geração de resíduos sólidos somente ao crescimento populacional, outro fator muito importante é o consumo. O consumo pode ser definido como a função da vida econômica que consiste na utilização direta, pela produção, das riquezas produzidas, também contribui para o aumento da geração de resíduos. Segundo Douglas (2007, p. 25), os padrões de consumo pouco se referem às necessidades e desejos do indivíduo, mas sim em virtude de pressões e expectativas de outras pessoas, que compõem a sociedade.

Ainda segundo Douglas (2007), "o consumo é o processo de transformar mercadorias em bem-estar". De acordo com Ortigoza e Cortez (2009), profundas inovações afetam o modo de consumo nesse início do século $X X I$, comércio pela internet, biotecnologias, novas técnicas de comunicação. A sociedade em expansão e influenciada pelo estilo de vida estadunidense, transforma o consumo em um vício, que é estimulado pelas forças do mercado, da moda e da propaganda. Esta sociedade passa a ser reconhecida, avaliada e julgada por aquilo que consome e a qualidade de vida passa a ser cada vez mais associada e reduzida às conquistas materiais. Um fato importante que resulta do aumento do consumo, principalmente por artigos descartáveis, embalagens e do descarte inadequado de resíduos sólidos é a poluição marinha, causada especialmente por resíduos plásticos que contribuem para a formação de ilhas de plástico e causa danos a vida marinha. Segundo Turra et al (2014) a produção de plástico no mundo cresceu de 1,5 milhão de toneladas no ano de 1950 para 280 milhões de toneladas no ano de 2012. Para o autor o aumento no volume de produção e a durabilidade do plástico estão relacionados ao acúmulo desses resíduos nos ambientes aquáticos e terrestres de todo o mundo. 
A gestão dos resíduos originados do pós-consumo, podem ser gerenciadas através do valioso instrumento chamado logística reversa (BRASIL, 2019) que, de acordo com o Ministério do Meio Ambiente (MMA), é um instrumento econômico e social, formado por ações e procedimentos, com o objetivo de viabilizar a coleta e restituição dos resíduos sólidos ao setor empresarial, para o devido reaproveitamento ou outra destinação ambientalmente adequada. A logística reversa é possível de ser implantada, uma vez que o produtor tem um sistema de logística para que seu produto possa chegar até o consumidor, ele pode fazer o caminho inverso, após o consumo de seu produto.

A logística reversa está sendo implantada no Brasil através de acordos setoriais, que, de acordo com o MMA, são atos de natureza contratual que são firmados entre poder público e fabricantes, importadores, distribuidores ou comerciantes, para que se faça cumprir a responsabilidade desses, com o ciclo de vida de seus produtos. Outro item de grande importância é a educação ambiental, tanto do tratamento dos resíduos sólidos, quanto do consumo consciente. $O$ artigo $5^{0}$ da PNRS integra a Política Nacional de Meio Ambiente e articula-se com outras políticas, sendo a Política Nacional de Educação Ambiental uma delas. A educação ambiental também é um instrumento da PNRS prevista em seu artigo 8 inciso VIII. A Política Nacional de Educação Ambiental (PNEA) foi instituída em 1999 (BRASIL, 1999), através da Lei Federal n. 9.795 e sancionada em 2002, pelo Decreto n. 4.281 (BRASIL, 2002). A PNEA aborda em seu segundo artigo que a educação ambiental é um componente essencial e permanente da educação nacional, devendo estar presente em todos os níveis e modalidades do processo educativo, em caráter formal e não formal. A PNEA aplica-se tanto a instituições públicas quanto particulares de ensino.

\section{MATERIAIS E MÉTODOS}

\section{1 Área de Estudo:}

A área em estudo está inserida na Região Metropolitana do Vale do Paraíba e Litoral Norte (RMVPLN) criada através de Legislação Estadual (BRASIL, 2012), mais precisamente representada pela Sub-região 5 que compreende os municípios de Caraguatatuba, Ilhabela, São Sebastião e Ubatuba, conforme ilustrado pela Figura 1. Trata-se de municípios do Litoral Norte do Estado de São Paulo, situados entre o Oceano Atlântico e a Serra do Mar. 


\subsection{Metodologia}

Figura 1 - Região Metropolitana do Vale do Paraíba e Litoral Norte. Região Metropolitana do Vale do Paraiba e Litoral Norte

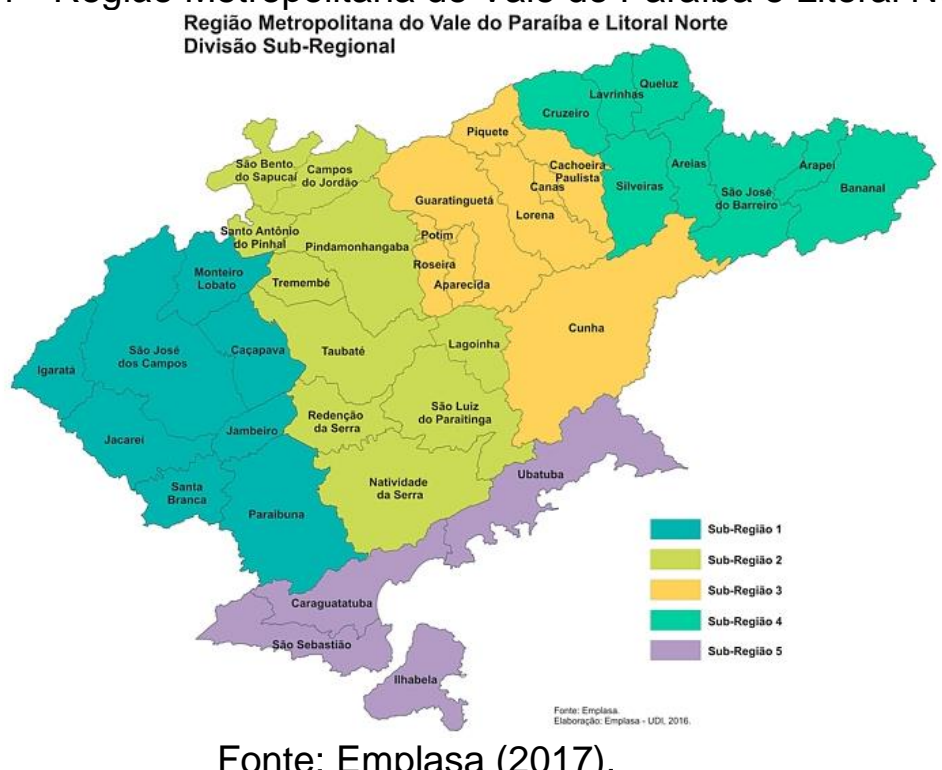

Fonte: Emplasa (2017).

O procedimento da pesquisa é do tipo estudo de caso, com abordagem qualiquantitativa. De acordo com Gerhardt e Silveira (2009, p. 32), a pesquisa qualitativa centra-se na compreensão e explicação das relações sociais, considerando os aspectos da realidade não quantificáveis e a pesquisa quantitativa enfatiza os atributos mensuráveis, o raciocínio dedutível e a lógica. A natureza da pesquisa aplicada que tem como objetivo a produção de conhecimentos dirigidos à solução de problemas específicos e com aplicação prática, envolvendo verdades e interesses locais (GERHARDT; SILVEIRA, 2009, p. 34). Com relação aos objetivos, segundo Gerhardt e Silveira (2009, p. 35), a pesquisa é exploratória, pois visa aumentar a familiaridade com o problema de forma a tornar mais explícito ou construir hipóteses. Dessa maneira o estudo é exploratório e envolveu levantamento bibliográfico e aplicação de questionário. O estudo de caso possui uma entidade bem definida em que não se pretende intervir sobre o objeto mas revelá-lo de acordo com a percepção do pesquisador (GERHARDT; SILVEIRA, 2009, p. 39). A pesquisa foi desenvolvida compreendendo as seguintes etapas detalhadas abaixo: i) coleta de dados, ii) análise dos dados, iii) resultados e discussão e iv) considerações finais.

\subsubsection{Coleta de dados:}

Os dados primários foram coletados por meio de um questionário estruturadoque foi elaborado com base no questionário do livro de BESEN et al. (2017). A partir dos dados levantados com a aplicação do questionário aos gestores de Resíduos Sólidos Urbanos (RSU) dos municípios foi possível a comparabilidade entre os municípios da região estudada. O questionário abrange aspectos como: institucional, relação com a sociedade e custos. 


\subsubsection{Análise dos dados:}

A análise dos dados foi realizada pela comparação entre os quatro municípios a partir de índices estabelecidos segundo Besen et al. (2017) e de dados da ABRELPE (Associação Brasileira das Empresas de Limpeza Pública e Resíduos Especiais). Para possibilitar algumas comparações e viabilizar as análises foram definidas variáveis classificadas como: $(A)$ institucionais, $(B)$ relação com a sociedade e $(C)$ custos.

A variável A1 - Plano de Gestão Integrada de Resíduos Sólidos. Foram analisados alguns aspectos do PMGIRS nas questões de: o município possui plano? O plano é intermunicipal? Foi construído de forma participativa? Essas questões foram analisadas segundo o índice de Besen.

A variável A2 - Coleta, Transporte e Tratamento de Resíduos Sólidos Urbanos, foi analisada a partir da comparação entre os 4 municípios e para a variável quantidade de Resíduos Sólidos Urbanos (RSU). Foi estabelecido um valor ideal de coleta de resíduos sólidos urbanos para ser comparado com o valor declarado de cada município. Esse valor ideal foi calculado com base na informação do Diagnóstico do SNIS (BRASIL, 2016), estimando a média de 0,94 kg/hab/dia de resíduos sólidos coletados. O valor ideal foi calculado com base na população de cada município, sendo referente ao ano de 2017, para os municípios de Caraguatatuba, Ilhabela e São Sebastião e de 2015 para o município de Ubatuba

A variável A3 - Existência de Coleta Seletiva, a análise foi realizada a partir da comparação entre a quantidade coletada de resíduos da coleta seletiva declarada e a quantidade ideal. Para a construção da variável quantidade ideal, foi utilizada a informação do Diagnóstico do SNIS de 2016 (BRASIL, 2016), sendo que a média nacional estimada é de $13,6 \mathrm{~kg} / \mathrm{hab} / \mathrm{ano}$ de resíduos da coleta seletiva, que compreende os materiais recicláveis. O valor ideal foi calculado com base na população de cada município, sendo referente ao ano de 2017, para os municípios de Caraguatatuba, Ilhabela e São Sebastião e de 2015 para o município de Ubatuba

A variável A4 - Atendimento a população (percentual de coleta), a análise foi realizada a partir da comparação entre os 4 municípios, com base na média nacional conforme SNIS de 2016 (BRASIL, 2016).

Para a análise da variável B1 - Educação/Divulgação, o questionário ofereceu 7 modalidades de ações e/ou divulgações, podendo ser assinaladas todas as opções praticadas pelo município. O percentual de atendimento às ações e divulgações referentes a coleta seletiva nos municípios estudados, foi calculado com base no percentual desenvolvido por Besen et al. (2017). Calculou-se o percentual de atendimento das ações tendo o máximo 7 atendimentos (100\%).

A avaliação da variável B2 - Participação e Controle Social, foi efetuada através da adaptação da base de dados segundo Besen et al. (2017). 
Para a análise da variável C1 - Custos, foi realizada a comparação entre os 4 municípios a luz da Política Nacional de Resíduos Sólidos e comparação entre dados SNIS de 2016 (BRASIL, 2016).

\section{RESULTADOS E DISCUSSÃO:}

Com o suporte da metodologia utilizada são apresentados e discutidos os resultados obtidos para cada indicador conforme os aspectos: institucional $(A)$, relação com a sociedade (B) e custos (C).

\section{A - Aspectos Institucionais:}

\section{A1 - Plano de Gestão Integrada de Resíduos Sólidos:}

A Tabela 1 mostra que os quatro municípios declararam possuir PMGIRS (Plano Municipal de Gestão Integrada de Resíduos Sólidos), que foram construídos com a participação social e encontram-se em execução.

Tabela 1- PMGIRS dos municípios estudados.

\begin{tabular}{|l|c|c|c|c|}
\hline \multicolumn{1}{|c|}{ Questões } & Caraguatatuba & Ilhabela & $\begin{array}{c}\text { São } \\
\text { Sebastião }\end{array}$ & Ubatuba \\
\hline $\begin{array}{l}\text { Existência do Plano de Municipal de Gestão } \\
\text { Integrada de Resíduos Sólidos }\end{array}$ & SIM & SIM & SIM & SIM \\
\hline A construção do PMGIRS, foi participativa? & SIM & SIM & SIM & SIM \\
\hline O PMGIRS está em execução? & SIM & SIM & SIM & SIM \\
\hline Avaliação & Favorável & Favorável & Favorável & Favorável \\
\hline
\end{tabular}

Fonte: Os autores.

Para realizar a avaliação do item A1 foi utilizada a publicação Gestão da coleta seletiva e de organização de catadores: indicadores e índices de BESEN (2017) e a partir da Tabela 2 foi possível avaliar cada município.

Tabela 2 - Índice Besen - PMGIR.

\begin{tabular}{|c|l|}
\hline Avaliação & \multicolumn{1}{|c|}{ Como avaliar } \\
\hline Muito Favorável & existência de Plano Intermunicipal e construção participativa. \\
\hline Favorável & existência de Plano Municipal com construção participativa. \\
\hline Desfavorável & existência de Plano Municipal sem construção participativa. \\
\hline Muito Desfavorável & não existência de Plano. \\
\hline
\end{tabular}

Fonte: Besen et al. (2017).

A importância do PMGIRS está prevista na PNRS (Política Nacional de Resíduos Sólidos) que estabelece o prazo máximo de 2 anos a partir da publicação da lei para que todos os municípios da União elaborem seus planos de resíduos. No caso dos municípios do Litoral Norte Paulista, este prazo foi atendido (BRASIL, 2010a). O município de Caraguatatuba publicou o plano por meio do Decreto; Ubatuba publicou através de Lei que institui a política municipal de resíduos sólidos; já os municípios de 
São Sebastião e llhabela ainda não publicaram seus planos. O município de São Sebastião está em fase de revisão do PMGIRS e segundo consulta à página de internet da Câmara Municipal o plano encontra-se aguardando parecer das comissões de Justiça e Meio Ambiente antes de ir para votação em plenário. Devido à proximidade e semelhança em diversos aspectos como: interferência devido a sazonalidade em períodos de veraneio, características físicas, dificuldade de implantação de aterro sanitário. Entre outros fatores, esses municípios deveriam levar em consideração a possibilidade da elaboração de um Plano Intermunicipal. O Plano sendo desenvolvido em conjunto com outros municípios possibilitaria a redução de custo, redução de tempo, compartilhamento de conhecimento, redução de recursos e mão de obra envolvidos, além de que esta modalidade está prevista na PNRS (Política Nacional de Resíduos Sólidos) e é considerada como prioritária para acessar os recursos da União (BRASIL, 2010a).

\section{A2 - Coleta, Transporte e Tratamento de Resíduos Sólidos Urbanos:}

Os quatro municípios declararam possuir área de transbordo utilizadas com a finalidade de otimizar o transporte. A coleta porta a porta é realizada com caminhão do tipo compactador e uma vez atingida a capacidade de coleta deste caminhão, ele é direcionado para a área de transbordo onde o mesmo é esvaziado. Todo o resíduo da área de transbordo é transferido para uma carreta com capacidade maior que a do caminhão compactador.

Os quatro municípios declararam destinar seus resíduos sólidos urbanos para Aterro Sanitário, localizado no município de Jambeiro, no estado de São Paulo.

O referido transporte utiliza a Rodovia dos Tamoios como rota para o transporte de seus resíduos.

No que se refere aos impedimentos ambientais e legais levantados no município para a implantação de Aterro Sanitário, os quatro municípios citaram a falta de área disponível e, Caraguatatuba e Ubatuba, levantaram a questão da dificuldade da obtenção de licença ambiental.

Os resultados referentes a quantidade coletada de resíduos sólidos urbanos, declarada pelos municípios e a quantidade ideal são apresentados na Figura 2, onde observa-se que o município de Ubatuba tem como base o ano de 2015 para seus cálculos. 
Figura 2 - Quantificação dos volumes coletados de RSU dos municípios analisados.

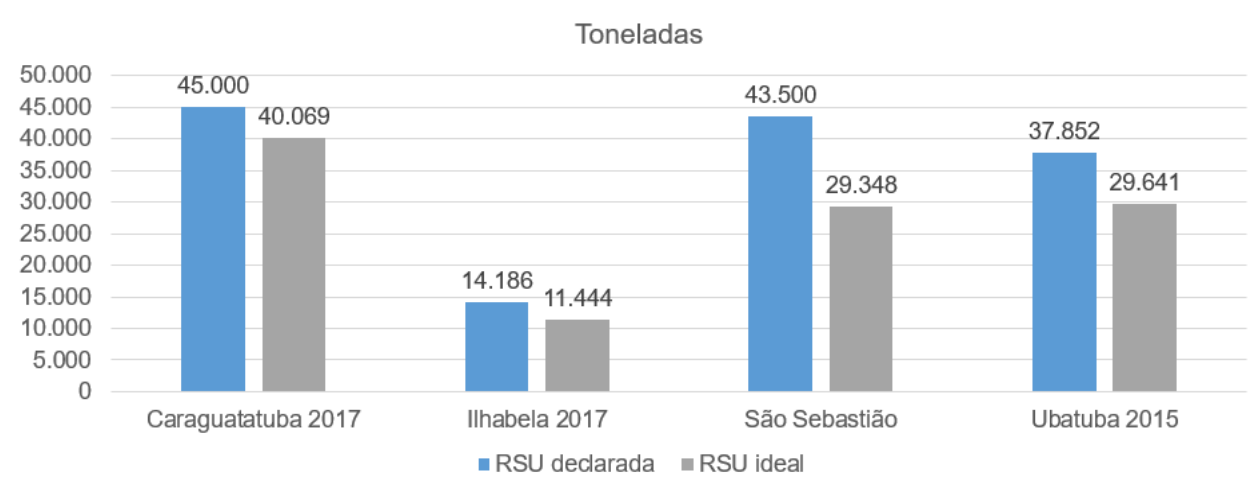

Fonte: Os autores.

Para os municípios estudados a quantidade coletada de resíduos sólidos urbanos declarada mostrou-se acima do indicador médio do Brasil, demonstrando que o sistema de gestão atende o item avaliado. Acredita-se que os valores declarados apresentaram-se superiores à média nacional de coleta, devido aos meses de veraneio compreendidos pelos meses de dezembro, janeiro e fevereiro.

No artigo 54 da PNRS (Política Nacional de Resíduos Sólidos) fica estabelecido que a disposição final ambientalmente adequada dos rejeitos deverá ser implantada em até quatro anos após a publicação da Lei (BRASIL, 2010a). Os quatro municípios atenderam devidamente o prazo estabelecido para a destinação dos seus resíduos para aterro sanitário: Ilhabela e São Sebastião em 2005, Ubatuba em 2009 e Caraguatatuba em 2013.

\section{A3 - Existência de Coleta Seletiva:}

Os quatro municípios declararam possuir coleta seletiva para a população urbana. Os municípios de Caraguatatuba, Ilhabela e São Sebastião possuem coleta seletiva nos próprios públicos. Os municípios de Caraguatatuba, São Sebastião e Ubatuba, disponibilizam a coleta seletiva em eventos públicos. Os municípios de Caraguatatuba e São Sebastião realizam a triagem de resíduos originados da limpeza pública, este item destaca a preocupação dos municípios em relação a gestão de resíduos sólidos, uma vez que esta tarefa apresenta bastante dificuldade.

A Figura 3 apresenta os resultados referentes a quantidade coletada de resíduos da coleta seletiva, declarada pelos municípios e a quantidade ideal. A quantidade ideal foi calculada com base na informação do Diagnóstico do SNIS de 2016 (BRASIL, 2016), que para o Brasil estima a média de $13,6 \mathrm{~kg} / \mathrm{hab} / \mathrm{ano}$ de resíduos da coleta seletiva. O valor ideal foi calculado com base na população de cada município, sendo referente ao ano de 2017, para os municípios de Caraguatatuba, Ilhabela e São Sebastião e de 2015 para o município de Ubatuba. O município de Ubatuba declarou, 
no questionário, a quantidade coletada referente ao ano de 2015 , portanto a população utilizada para o cálculo do ideal foi de 2015, para este município.

Figura 3 - Quantificação dos volumes da coleta seletiva para os municípios estudados.

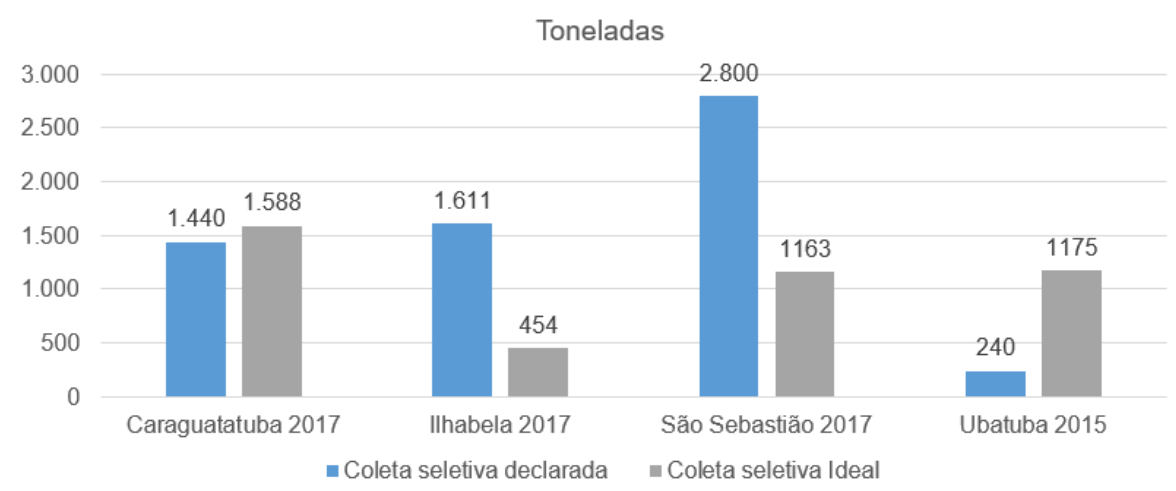

Fonte: Os autores.

Na Figura 3, verifica-se que o município de Caraguatatuba se aproxima da média nacional. O município de Ilhabela coleta 3 vezes mais, São Sebastião 2,5 vezes mais e o município de Ubatuba declara coletar 5 vezes menos do que o esperado pela média nacional, segundo o Diagnóstico do SNIS (Sistema Nacional de Informações sobre Saneamento) de 2016 (BRASIL, 2016).

A coleta seletiva é um instrumento muito importante para a elaboração do PMGIRS pelos municípios e conforme disposto no artigo 36, inciso segundo da PNRS, a política traz que cabe ao titular dos serviços públicos de limpeza urbana e de manejo de resíduos sólidos, a responsabilidade em estabelecer o sistema de coleta seletiva, quando houver o PMGIRS, que é o caso dos municípios em questão.

\section{A4 - Atendimento da População:}

\section{Resíduos Sólidos Urbanos:}

O tipo de coleta praticado pelos quatro municípios é o mesmo: coleta porta a porta, o que varia é o percentual de atendimento à população urbana. Os municípios de Caraguatatuba e São Sebastião declararam que a cobertura de coleta é de $100 \%$ da população urbana, Ubatuba $98 \%$ e o município de Ilhabela declara cobertura de 95\%. Esses são percentuais que representam bons resultados se comparados a média nacional de 98,6\%, conforme publicado pelo SNIS (BRASIL, 2016). A Figura 4, apresenta os resultados de percentual de coleta realizado pelos municípios estudados e a média nacional segundo o Diagnóstico SNIS 2016. 
Figura 4 - Percentuais da coleta de RSU nos municípios estudados.

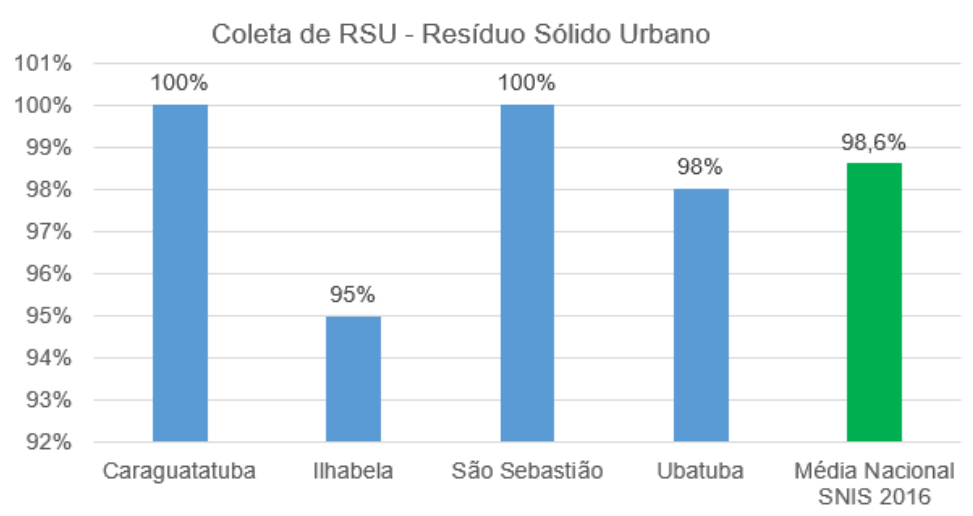

Fonte: Os autores.

\section{Coleta Seletiva:}

Os quatro municípios declararam realizar coleta porta a porta de resíduos recicláveis. A Figura 5 apresenta os resultados conforme declarado por cada município no questionário respondido.

Figura 5 - Percentuais da coleta seletiva nos municípios estudados.

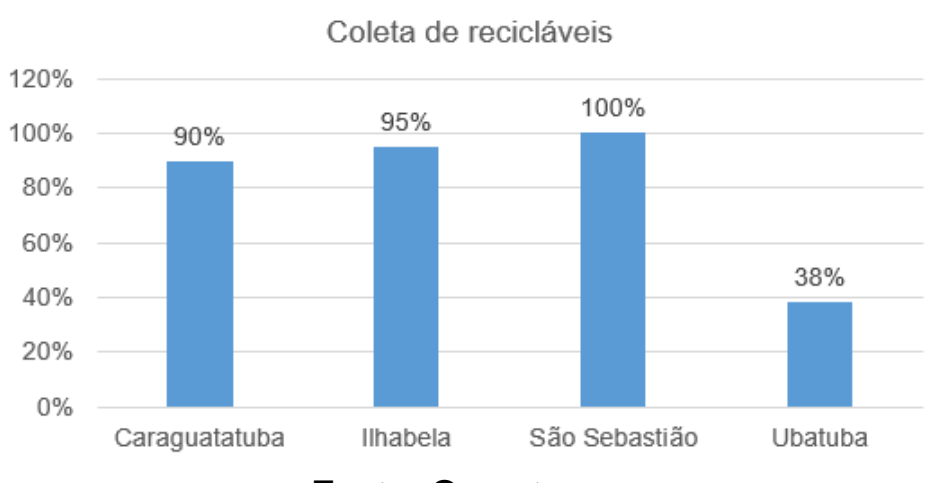

Fonte: Os autores.

De acordo com Besen et al. (2017) os municípios de Caraguatatuba, Ilhabela e São Sebastião possuem uma cobertura favorável e o município de Ubatuba apresenta percentual de cobertura muito desfavorável. O município de Ubatuba declarou que realiza a coleta de recicláveis porta a porta somente no perímetro urbano, que segundo o PMGIRS do município declara atender 38\% da população urbana do município.

A universalização dos serviços públicos de coleta de resíduos sólidos urbanos está prevista nas Políticas Nacionais de Saneamento Básico (BRASIL, 2007) e de Resíduos Sólidos (BRASIL, 2010a), que traz em um de seus objetivos, conforme $7^{\circ}$ artigo inciso $X$ : a regularidade, continuidade, funcionalidade e universalização da prestação dos serviços públicos de limpeza urbana e de manejo de resíduos sólidos. Neste contexto é possível avaliar que o município de São Sebastião já atende este objetivo, os municípios de Ilhabela e Caraguatatuba estão bem próximos de atender e o município de Ubatuba atende $98 \%$ da coleta de RSU (Resíduos Sólidos Urbanos); 
porém, apresenta um déficit em relação aos demais municípios da região quanto a coleta de recicláveis.

\section{B - Aspectos de Relação com a Sociedade:}

\section{B1 - Educação / Divulgação:}

Os quatro municípios declararam possuir ações ou atividades de educação e divulgação da coleta seletiva. A Tabela 3 apresenta as respostas do questionário aplicado e o percentual de atendimento pôde ser avaliado com base nos níveis de classificação apresentados na Tabela 4.

Tabela 3 - Educação / Divulgação da coleta seletiva dos municípios estudados.

\begin{tabular}{|l|c|c|c|c|}
\hline $\begin{array}{l}\text { Quais as ações/atividades de } \\
\text { educação e divulgação realizadas } \\
\text { em prol da coleta seletiva }\end{array}$ & Caraguatatuba & Ilhabela & São Sebastião & Ubatuba \\
\hline Campanhas pontuais & SIM & SIM & SIM & SIM \\
\hline Campanhas permanentes & SIM & NÃO & SIM & SIM \\
\hline Atividades com alunos em escolas & SIM & SIM & SIM & SIM \\
\hline $\begin{array}{l}\text { Atividades de sensibilização dos } \\
\text { funcionários Municipais }\end{array}$ & NÃO & SIM & SIM & NÃO \\
\hline Elaboração de folhetos & SIM & NÃO & SIM & SIM \\
\hline $\begin{array}{l}\text { Inserções em programas de rádio e } \\
\text { TV }\end{array}$ & SIM & NÃO & SIM & SIM \\
\hline $\begin{array}{l}\text { Elaboração de sites de educação } \\
\text { ambiental }\end{array}$ & SIM & NÃO & NÃO & SIM \\
\hline Percentual de atendimento & $86 \%$ & $43 \%$ & $86 \%$ & $86 \%$ \\
\hline
\end{tabular}

Fonte: Os autores.

O cálculo do percentual de atendimento das ações tendo o máximo 7 atendimentos, $100 \%$, conforme o número de opções oferecidas no questionário.

Tabela 4 - Níveis de classificação com base nos percentuais de ações de divulgação sobre a coleta seletiva.

\begin{tabular}{|l|l|}
\hline \multicolumn{1}{|c|}{ Avaliação } & \multicolumn{1}{|c|}{$\begin{array}{c}\text { Percentual de } \\
\text { atendimento }\end{array}$} \\
\hline Muito Favorável & maior ou igual à $80 \%$ \\
\hline Favorável & de $50,1 \%$ à $79,9 \%$ \\
\hline Desfavorável & de 20,1 à $50 \%$ \\
\hline Muito Desfavorável & menor igual à $20 \%$ \\
\hline
\end{tabular}

Fonte: Besen et al., 2017.

Com base nos níveis de classificação da Tabela 4, observa-se que o município de Ilhabela está em desvantagem em relação aos demais, que atingiram o nível muito favorável, o que contribui para a gestão da coleta seletiva dos municípios. 
O artigo $5^{\circ}$ da PNRS, integra a Política Nacional de Meio Ambiente e articula-se com outras políticas, a Política Nacional de Educação Ambiental (PNEA) encontra-se nas políticas articuladas pela PNRS. A educação ambiental também é um instrumento da PNRS prevista em seu artigo 8ํinciso VIII. Como conteúdo mínimo, o PMGIRS Plano Municipal de Gerenciamento Integrado de Resíduos Sólidos - precisa prever programas e ações de educação ambiental que promovam a não geração, a redução, a reutilização e a reciclagem de resíduos sólidos, conforme previsto no artigo 19 inciso $X$ da Lei Federal n. 12.305 de 2010 (BRASIL, 2010a). O Governo Federal, por meio do Ministério de Meio Ambiente possui uma ação que apoia a implantação da PNRS através da Educação Ambiental e Comunicação Social, conhecida como Plataforma Virtual Educares. A plataforma acredita que a educação ambiental e a comunicação social são complementares e indispensáveis para a gestão de RSU (Resíduos Sólidos Urbanos) nos municípios.

\section{B2 - Participação e Controle Social:}

Esse atributo visa medir a existência ou não de canais efetivos de participação da sociedade civil na gestão municipal da coleta seletiva. A PNRS (Política Nacional de Resíduos Sólidos) prevê o direito da sociedade à informação e ao controle social, em seus princípios e objetivos. Segundo Besen et al. (2017), a participação da sociedade garante a efetividade da coleta seletiva e ainda realiza o controle social dos PMGIRS (Plano Municipal de Gestão Integrado de Resíduos Sólidos). A partir das respostas obtidas para cada município foi elaborada a Tabela 6 , a qual foi adaptada com base na publicação Gestão da coleta seletiva e de organização de catadores: indicadores e índices de Besen et al. em 2017, para realizar a avaliação. A Tabela 5 apresenta os resultados relacionados a participação social conforme declarado por cada município.

Tabela 5 - Resultados da participação social na gestão da coleta seletiva nos municípios.

\begin{tabular}{|c|c|c|c|c|}
\hline $\begin{array}{l}\text { Quais os canais efetivos de } \\
\text { participação da sociedade civil } \\
\text { na gestão municipal da coleta } \\
\text { seletiva. }\end{array}$ & Caraguatatuba & Ilhabela & São Sebastião & Ubatuba \\
\hline Comitês Gestores em atividade & SIM & NÃO & SIM & SIM \\
\hline Comitês Gestores inativo & NÃO & NÃO & NÃO & NÃO \\
\hline $\begin{array}{l}\text { Câmaras Técnicas ou Grupos de } \\
\text { Trabalho de resíduos em } \\
\text { Conselhos de Meio } \\
\text { Ambiente/Comitês de Bacia e } \\
\text { outros em atividade }\end{array}$ & SIM & SIM & SIM & SIM \\
\hline $\begin{array}{l}\text { Câmaras Técnicas ou Grupos de } \\
\text { Trabalho de resíduos em } \\
\text { Conselhos de Meio } \\
\text { Ambiente/Comitês de Bacia e } \\
\text { outros inativo }\end{array}$ & NÃO & NÃO & NÃO & NÃO \\
\hline Avaliação & Muito Favorável & Favorável & Muito Favorável & Muito Favorável \\
\hline
\end{tabular}

Fonte: Os autores. 
Tabela 6 - Indicadores da gestão de coleta seletiva e da organização de catadores

\begin{tabular}{|l|l|}
\hline \multicolumn{1}{|c|}{ Avaliação } & \multicolumn{1}{c|}{ Atendimento } \\
\hline Muito Favorável & $\begin{array}{l}\text { existência de mais de uma instância em } \\
\text { funcionamento }\end{array}$ \\
\hline Favorável & existência de uma instância em funcionamento \\
\hline Desfavorável & existência de instância porém sem funcionamento \\
\hline Muito Desfavorável & não existência de instância de participação \\
\hline
\end{tabular}

Fonte: Adaptada de Besen et al. (2017).

A PNRS (Política nacional de Resíduos Sólidos), prevê o direito da sociedade à informação e ao controle social. No artigo $6^{\circ}$ inciso $X$, como princípio traz o direito da sociedade à informação e ao controle social. No artigo $8^{\circ}$ incisos XIII e XIV prevê como instrumentos, os conselhos de meio ambiente e os órgãos colegiados municipais que são destinados ao controle dos serviços de RSU (Resíduos Sólidos Urbanos). O artigo 14 parágrafo único, assegura ampla publicidade ao conteúdo dos planos de resíduos sólidos e controle social na formulação, implementação e operacionalização desses, previstos na Lei Federal n. 10.650 de 2003 (BRASIL, 2003), que dispõe sobre o acesso público aos dados e informações ambientais disponíveis no SISNAMA (Sistema Nacional do Meio Ambiente) e Lei Federal n. 11.445 de 2007 (BRASIL, 2007), em seu art. 47 assegura a representação dos usuários de serviços de saneamento básico.

\section{C - Aspecto Custos:}

\section{C1 - Cobrança Pelo Serviço de Resíduos Sólidos Urbanos:}

A PNRS prevê em seus objetivos, no artigo sétimo, a sustentabilidade financeira da gestão de resíduos sólidos no município.

Está previsto ainda, no capítulo V da PNSB (Política Nacional de Saneamento Básico), Lei Federal n. 11.445 de 2007 (BRASIL, 2007), que a função da regulação deverá atender ao objetivo de definir tarifas que assegurem o equilíbrio econômico financeiro e a modicidade tarifária, garantindo a eficiência e a eficácia dos serviços.

Segundo divulgado pelo Diagnóstico de Manejo de Resíduos Sólidos Urbanos de 2016, pelo SNIS (Sistema Nacional sobre Saneamento), 43,1\% dos municípios brasileiros cobram pelo serviço e $56,9 \%$ declararam não cobrar. Dentre os municípios que realizam a cobrança, 86,1\% declararam realizar a cobrança da taxa de manejo de resíduos sólidos através do IPTU. Os municípios de Ilhabela, São Sebastião e Ubatuba realizam a cobrança da mesma forma que maioria dos municípios do país que realiza a cobrança. Ilhabela e Ubatuba declararam que a taxa é insuficiente para cobrir os custos gerados. O município de São Sebastião declara que a taxa cobre os custos com o manejo de resíduos sólidos urbanos. Sendo assim, 3 dos 4 municípios estudados não estão atualmente garantindo a sustentabilidade financeira no manejo 
de resíduos sólidos urbanos. A Tabela 7, apresenta os dados referentes ao tipo de cobrança realizado em cada município.

Tabela 7 - Modalidades de cobrança pelos serviços de manejo dos RSU.

\begin{tabular}{|l|c|c|c|c|}
\hline $\begin{array}{l}\text { Qual a forma de cobrança pelos serviços } \\
\text { de manejo de resíduos sólidos urbanos? }\end{array}$ & Caraguatatuba & Ilhabela & $\begin{array}{c}\text { São } \\
\text { Sebastião }\end{array}$ & Ubatuba \\
\hline $\begin{array}{l}\text { cobrança de Taxa específica de lixo que } \\
\text { cubra o custo do serviço de coleta, } \\
\text { transporte e tratamento dos resíduos sólidos } \\
\text { urbanos. }\end{array}$ & NÃO & NÃO & NÃO & NÃO \\
\hline $\begin{array}{l}\text { cobrança de Taxa específica de lixo que não } \\
\text { cubram o custo do serviço de coleta, } \\
\text { transporte e tratamento dos resíduos sólidos } \\
\text { urbanos. }\end{array}$ & NÃO & NÃO & NÃO & NÃO \\
\hline $\begin{array}{l}\text { cobrança de Taxa no IPTU, que cubra todo o } \\
\text { custo do serviço. }\end{array}$ & NÃO & NÃO & SIM & NÃO \\
\hline $\begin{array}{l}\text { cobrança de Taxa no IPTU, que não cubram } \\
\text { os custos do serviçO. }\end{array}$ & NÃO & SIM & NÃO & SIM \\
\hline Não existe cobrança. & SIM & NÃO & NÃO & NÃO \\
\hline
\end{tabular}

Fonte: Os autores.

\section{CONSIDERAÇÕES FINAIS}

Com base nos resultados apresentados foi possível identificar que os municípios do litoral norte paulista cumprem a PNRS (Política Nacional de Resíduos Sólidos) no que tange à disposição ambientalmente adequada dos resíduos sólidos urbanos, uma vez que desativaram seus lixões dentro do prazo estipulado pela PNRS e passaram a dispor os resíduos em aterros sanitários licenciados, apesar da distância percorrida para tal. Os quatro municípios declaram praticar a gestão democrática construindo seus PMGIRS (Planos Municipais de Gerenciamento Integrado de Resíduos Sólidos) com a participação da população que tem todo o direito e obrigação de opinar sobre as questões relacionadas aos resíduos sólidos urbanos, afinal a população como consumidor, é responsável pelos RSU gerados.

Através da análise dos indicadores obtidos a partir dos dados primários, foi possível observar que o município que mais atende a PNRS (Política Nacional de Resíduos Sólidos), avaliado pelos índices de Besen et al. (2017), é o município de São Sebastião, seguido pelos municípios de Caraguatatuba e Ilhabela, que demostraram semelhança e por último o município de Ubatuba que obteve os índices mais baixos.

Os quatro municípios demonstraram através do percentual de coleta dos RSU uma boa gestão no atendimento à população, sendo os municípios de Caraguatatuba e São Sebastião superior à média nacional.

$\mathrm{Na}$ questão relacionada à educação e divulgação, somente o município de Ilhabela mostrou-se desfavorável; porém, em cidades de veraneio como esta, a educação ambiental precisa chegar aos turistas, sendo trabalhadas nas praias e melhorando assim, a gestão do resíduo marinho que atinge tanto questões turísticas 
relacionadas à beleza e à qualidade das praias como a vida marinha. No tema educação ambiental, também acredita-se que deva ser trabalhada a questão sobre o consumo consciente. O aumento de consumo não é o único contribuinte para a geração de resíduos, mas se bem trabalhado contribui para a redução de geração de RSU. A educação com foco em consumo consciente é capaz de auxiliar a gestão e gerenciamento de RSU (Resíduos Sólidos Urbanos) no atendimento a PNRS (Política Nacional de Resíduos Sólidos), que define a ordem de prioridade a ser observada: não geração, redução, reutilização, reciclagem, tratamento dos resíduos sólidos e a disposição final ambientalmente adequada dos rejeitos.

As políticas públicas dos municípios podem ser melhor estruturadas a fim de atingir as diretrizes da PNRS e assim melhorar a gestão dos RSU nos municípios. Somente no município de Ubatuba foi identificada a Politica Municipal de Resíduos Sólidos, sendo que os demais possuem decretos ou somente planos. As políticas públicas dos municípios do Litoral Norte Paulista devem se apoderar do valioso instrumento chamado logística reversa e ainda desenvolver mecanismos que incentivem a prática da coleta seletiva, através das cooperativas de catadores, de modo a desenvolver esses profissionais, tornando a atividade mais digna e rentável. $O$ fato desses quatro municípios possuírem as mesmas características físicas pode ser uma excelente justificativa para os municípios se integrarem e optarem por soluções consorciadas intermunicipais, iniciando com a elaboração e implantação de um Consórcio intermunicipal (BRASL, 2005), para a destinação dos resíduos sólidos, que além de facilitar a gestão também prioriza a captação de recursos da União.

\section{REFERÊNCIAS}

BESEN, Gina R. et al. Gestão da coleta seletiva e de organizações de catadores: indicadores e índices de sustentabilidade. São Paulo: Faculdade de Saúde Pública/USP, 2017. Disponível em:

<http://www.iee.usp.br/pics/sites/default/files/livro_GestaoColetaSeletivalEE-USPedicao-pd.pdf $>$. Acesso em: 23 de jan. de 2018.

BETIO, M. M.; SANTOS, M. M. Contaminação das águas subterrâneas por lixões desativados: Avaliação da antiga área de disposição final de resíduos sólidos de Rolândia - PR. In: CONGRESSO BRASILEIRO DE ÁGUAS SUBTERRÂNEAS. 19., 2016, Campinas. Anais..., Campinas, 2016. Disponível em: $<$ https://aguassubterraneas.abas.org/asubterraneas/article/view/28753/18655>. Acesso em: 07 de out. 2018.

BRASIL. Lei o 12.305, de 02 de janeiro de 2010. Institui a política nacional de resíduos sólidos; altera a lei ํㅜ 9.605, de 12 de fevereiro de 1998. Diário Oficial da União, Brasília, 2010a.

BRASIL. Lei $\mathrm{n}^{\circ}$ 11.445, de 5 de janeiro de 2007. Estabelece diretrizes nacionais para o saneamento básico; altera as Leis nos 6.766, de 19 de dezembro de 1979, 8.036, de 11 de maio de 1990, 8.666, de 21 de junho de 1993, 8.987, de 13 de fevereiro de 
1995; revoga a Lei no 6.528, de 11 de maio de 1978; e dá outras providências. Diário Oficial da União, Brasília, 2007.

BRASIL. Decreto n. 7.404 de 23 de dezembro de 2010. Regulamenta a Lei $\mathrm{n}^{\circ}$ 12.305, de 2 de agosto de 2010. Diário Oficial da União, Brasília, 2010b. Disponível em: <http://www.planalto.gov.br/ccivil_03/_ato2007-2010/2010/Decreto/D7404.htm>. Acesso em: 05 out. 2017.

BRASIL. Lei no 10.650, de 16 de abril de 2003. Dispõe sobre o acesso público aos dados e informações existentes nos órgãos e entidades integrantes do Sisnama. Diário Oficial da União, Brasília, 2003.

BRASIL. Lei n. 9.795, de 27 de abril de 1999. Dispõe sobre a educação ambiental, institui a Política Nacional de Educação Ambiental e dá outras providências. Diário Oficial da União, Brasília, 1999.

BRASIL. Decreto no 4.281, de 25 de junho de 2002. Regulamenta a Lei no 9.795, de 27 de abril de 1999, que institui a Política Nacional de Educação Ambiental, e dá outras providências. Diário Oficial da União, Brasília, 2002.

BRASIL. Lei no 11.107, de 6 de abril de 2005. Dispõe sobre normas gerais de contratação de consórcios públicos e dá outras providências. Diário Oficial da União, Brasília, 2005.

BRASIL. Lei complementar no 1.166, de 9 de janeiro de 2012. Cria a região metropolitana do Vale do Paraíba e Litoral Norte, e dá providências correlatas. Diário Oficial da União, Brasília, 2012.

BRASIL. Ministério das Cidades. SNIS - Diagnóstico do Manejo de Resíduos

Sólidos Urbanos - 2016. 2016. Disponível em: <http://www.snis.gov.br/diagnosticoresiduos-solidos/diagnostico-rs-2016>. Acesso em 20 de mai. 2018.

BRASIL. Ministério do Meio Ambiente. Logística Reversa. Disponível em: <http://www.mma.gov.br/cidades-sustentaveis/residuos-perigosos/logistica-reversa> Acesso em 21 de jan. 2019.

DOUGLAS, Mary. O Mundo dos Bens, Vinte Anos Depois. Horizontes Antropológicos, ano 13, n. 28, p. 17-32, jul. /dez. 2007. Disponível em: <http://www.scielo.br/pdf/ha/v13n28/a02v1328.pdf>. Acesso em: 29 dez. 2018.

EMPRESA PAULISTA DE PLANEJAMENTO METROPOLITANO S.A. - EMPLASA. (São Paulo, SP). Região Metropolitana do Vale do Paraíba e Litoral Norte: divisão Sub-Regional. São Paulo, 2017. Disponível em: <https://emplasa.sp.gov.br/RMVPLN>. Acesso em: Acesso em: 29 dez. 2018.

GERHARDT, Tatiana Engel; SILVEIRA, Denise Tolfo. Métodos de Pesquisa. Porto Alegre: Editora da UFRGS, 2009.

MARICATO, Ermínia. Brasil, cidades: alternativas para a crise urbana. Petrópolis: Vozes, 2001.

ORTIGOZA, S. A. G.; CORTEZ, A.T.C. (Org.). Da produção ao consumo: impactos socioambientais no espaço urbano. São Paulo: Cultura Acadêmica, 2009. 
TURRA, A. et al. Three-dimensional distribution of plastic pellets in sandy beaches: shifting paradigms. Sci. Rep., v. 4, n. 4435, 2014. Disponível em:

<https://www.nature.com/articles/srep04435>. Acesso em: 15 de jan. 2019. 